Fig.1. Typical stages of a compaction process

During the last twenty years, several research groups have developed different numerical models to capture the evolution of the most relevant properties such as density and applied forces, during the compaction process. Most of them [2-9] have concentrated their efforts on the numerical simulation of the compaction itself and some [10-12] have included the transfer stage. However, die filling has been little analysed. The reasons are diverse: on one hand the difficulty to obtain reliable experimental results and on the other the great difficulties found when trying to simulate large movements with the numerical tools developed so far. In the context of powder metallurgy, the most relevant results, in both experimental and numerical fields, have been developed by A.C.F. Cocks and his co-workers [13-16]. They have developed and built an experimental system in a 


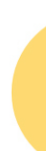
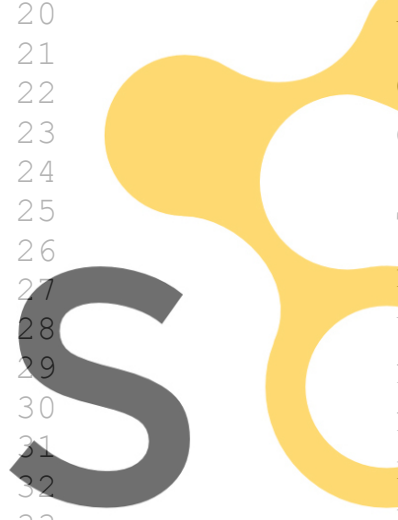

Begister for free at

vacuum chamber so that tests can be conducted in air or in vacuum. More importantly, they clarified the behaviour of the powder during filling; introducing the concepts of critical shoe velocity (the velocity above which incomplete filling is achieved) and the influence of air flow and pressure.

In the general context of granular systems, numerical simulation methodologies are many and wide ranging: Monte Carlo methods [17,18], Cellular Automata [19,20], Diffusing Void Model [21,22], Steepest Descent [23, 24], Molecular Dynamics (MD), Even Driven molecular dynamics (ED) [25,26], Discrete Element Method (DEM) [27]. In powder metallurgy, the most relevant results found in the literature [13-15], suggest the use of DEM to study the behaviour of powder during both filling and powder transfer.

Another alternative, in which the present work is framed, is the so-called Particle Finite Element Method, proposed initially in [28,29] for fluid mechanics problems. In this method, the motion of some individual particles is followed and, consequently, the nodes in a finite element mesh can be viewed as moving "particles". The motion of the mesh discretizing the total domain is also followed during the transient solution. It should be emphasised that the phenomenological behaviour of the particle is captured by means of the classical tools of the continuum mechanics; i.e. large strain kinematics, dissipative constitutive models, contact friction models, among others.

\section{The present paper deals with the experimental and numerical aspects of die filling} modelling understanding and filling is proposed finite elerne modeled numericalpredictions are comparetro
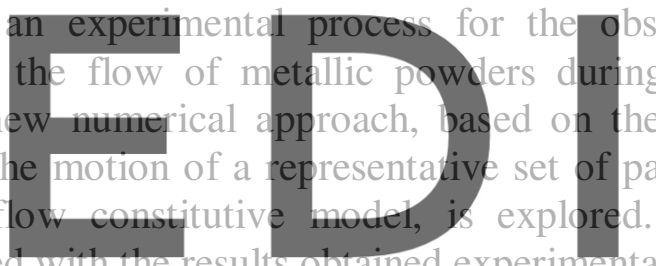

\section{https/Www.scipedia.com to download the version without the watermark
2. Experimental study and flow descriptions}

With the aim of improving the understanding of granular systems, in the context of powder metallurgy, experimental research about the flow and die filling mechanisms is considered. This part of the work focuses on how parameters such as powder shape and size, shoe speed $\left(\mathrm{v}_{\mathrm{s}}\right)$ and die geometry have an effect on properties as the final packing density [33], the kinetic energy of the particle system, and the wall-particle interaction factor. These properties eventually could modify the optimum powder particle distribution inside the die that must result in distorting the mechanical properties of the part during and after compaction [31,32].

\section{Fig. 2}

Experimental system. 1) High speed camera. 2) Transparent shoe. 3) Transparent die. 4) Control unit. 5) pneumatic system

In order to carry out this study, we have designed an experimental apparatus shown in Fig. 2 and consisting of a horizontal shoe and a vertical die; both of them transparent. The shoe is pneumatically activated by a monitoring system that allows a high level of precision. The speeds implemented on the shoe are 0.05 , $0.1,0.2,0.3,0.4$ and $0.5 \mathrm{~m} / \mathrm{s}$ and the powder flow is captured using a high speed video camera ( $80 \mathrm{fps})$. 
Four different materials have been used: coloured sand, spheroidal copper powder, irregular copper powder and irregular iron powder (sponge iron). Fig.3 shows the morphology of these powders and Table I shows their physical and morphological properties.

Fig.3. Images of various powders used

Table I. Physical and morphological powder properties

Three powder flow regimes have been observed as a function of the filling speed and the size of the particles. They are represented in Fig.4 The points in this figure correspond to the experimental conditions of the different die filling experiments that have been carried out. Lines $\mathrm{C}_{1}$ and $\mathrm{C}_{2}$ separate qualitatively the regions where different flow regimes have been observed. Both small particles and small shoe speed promote the establishment of a regime of discrete avalanches (region I). However, a continuous flow regime is observed at high filling speeds and/or with large particles (region III). The transition from the discrete to the continuous regime is not well delimited and takes into account an area of intermittent flow sharing properties from both regimes (region II).

Fig.4. Observed flow regimens for various irregular particle sizes and shoe velocities

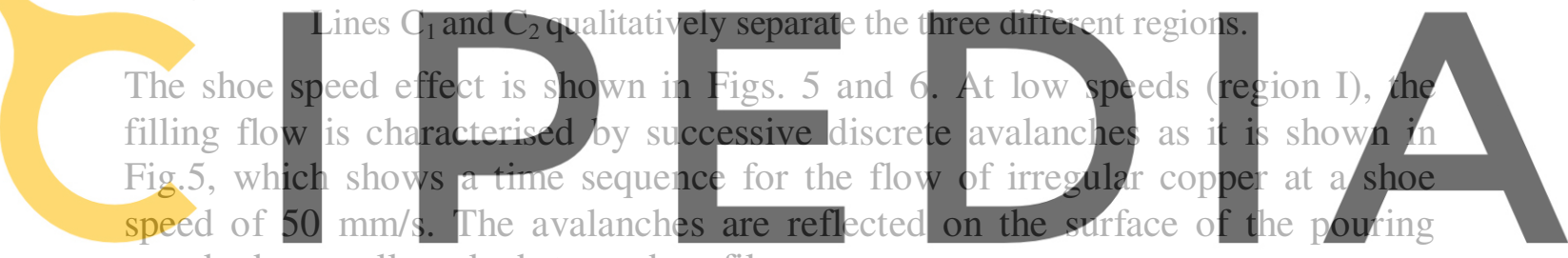

powder by a well marked stepped profile

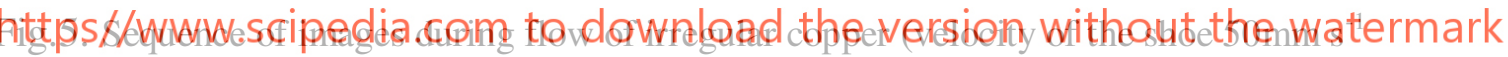
). The arrows indicate the presence of avalanches.

As the speed increases, the powder flow becomes progressively more continuous (region II), this can be observed in Fig.6, which shows a time sequence for the flow of irregular copper at a shoe speed of $300 \mathrm{~mm} / \mathrm{s}$. This intermittent regime is characterized by the presence on the surface profile of a higher number of steps of smaller height. The size of the particles at a given speed also affects the kind of flow. When the powder particles are small their surface area per unit volume is high; consequently, internal friction is also high giving rise to a discontinuous flow regime. The smaller internal friction when particles are large explains the continuous flow experimentally observed.

Fig.6. Sequence of images during flow of irregular copper (velocity of the shoe $300 \mathrm{~mm}$ $\mathrm{s}^{-1}$ ). The arrow indicate the presence of several small avalanches.

The morphology of the powder also affects the filling regime and plays and important role for determining the kind of flow. A spheroidal morphology favours a flow with a continuous regime while an irregular morphology favours a flow with a discrete avalanches regime. This behaviour is due to the degree of internal friction among the particles. Spheroidal copper presents a continuous filling regime even at low filling speeds; this can be observed in Fig.7. 
In the case of the discrete avalanches regime, the material flows from the shoe to the die not in a continuous or progressive manner- as is the case of the continuous regime- but there are perturbations in the flow as shown in Fig.5. When an avalanche takes place, a deforming shear mechanism is activated along a specific narrow band; along this band a block of undeformed powder slides into the die. In this band the friction stresses are overcome by the weight of the block of powder. The kinetic energy transferred to the powder by the shoe alters the static equilibrium and facilitates the powder flow.

The formation of avalanches can be better observed by filling the shoe with alternated layers of irregular iron and copper powders. When the flow of the powder takes place, the avalanches occur right from the start as shown in Fig.8. In the initial transitory state, the powder shears from the frontal wall of the shoe and from the rest of the powder mass that has not reached the entrance of the die yet, so there can be several shearing bands acting simultaneously. In the case presented in Fig.8, three active shearing bands can be distinguished in the powder mass. As we can observe in Fig.9, if the speed of the shoe is slow enough the powder flow reaches a state in which there is only one active shear band and the

Theoretical approaches to the discrete avalanches regime [35] predict that these must be formed by monolayers of powder. However, this study and other experimental studies prior to this one [36,37], show that the avalanches are made of bands with a finite width equivalent to between 8 to 12 monolayers of particles.

Fig.10. Width variation of three independent shearing bands

The high-speed video camera has enabled the study of the nucleation and posterior evolution of the shear bands. Fig. 10 shows, for an irregular iron powder, the width variation of three independent shearing bands during their time of activity. The bands reach from a very early stage an average width of about 1,8 $\mathrm{mm}$ equivalent in this case to 8 or 9 monolayers of iron powder. In these shearing bands are concentrated higher deformation speeds than in the rest of the material so they act as deformation concentrators and they facilitate the detachment of the available material between them and the free surface. 


\section{Numerical modelling.}

In powder metallurgy, relevant industrial problems associated with filling process have been observed to occur at high shoe speeds $[48,14,15]$, which, according to the experiments, can be associated to the continuous flow regime. For this reason in this work, the numerical simulations will focus on this continuous regime.

\subsection{Model for Numerical Simulation.}

As it was briefly mentioned in section 1, in the framework of granular systems, numerical simulation methodologies are many and wide ranging. However, in the context of powder metallurgy, only few of them have been explored. This is the case of DEM. This method can be understood as an alternative to circumvent the intrinsic limitations of the classical Finite Element Method when the phenomena, as in powder filling, involve large movements and deformations [13-15]. In DEM, the elementary units of granular materials are mesoscopic grains which deform under stress. Since the realistic modelling of the deformations of the particles (simply referred as balls) is much too complicated, the interaction force, related to the overlap of two particles, is often modelled with springs and dashpots. The total force acting on an individual ball determines the positioning and motion of the ball. Both the balls and the walls of the die can be assigned basic properties such as size and stiffness and also properties such as friction and damping coefficients. To solve the associated dynamic system of equations, an explicit

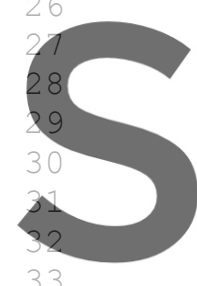

integration

framework

appear as st

applications

incorporatin
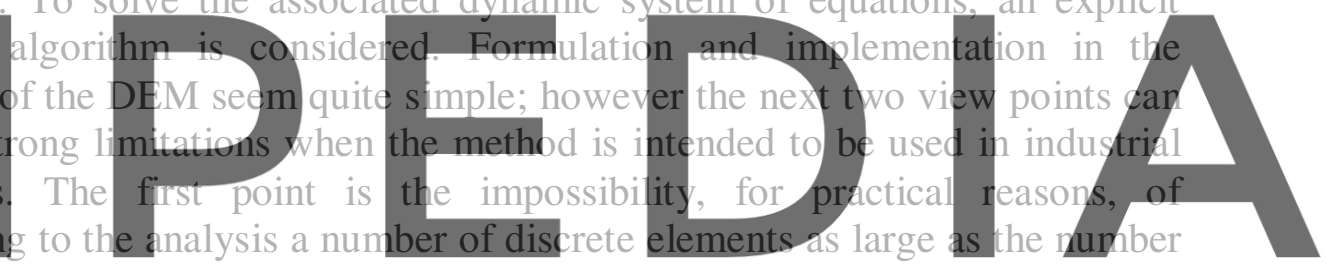

of the particles involved in the process. This point forces a detailed study of the

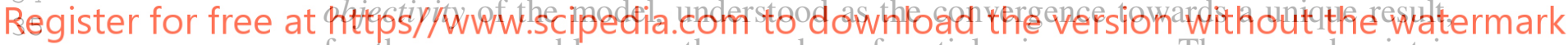
for the same problem, as the number of particles increases. The second point is the computational cost, in which the explicit integration of the dynamic equations,

via the finite difference method, imposes a severe limitation in the time length used for the computation. The resolution of the contacts between particles, that includes search algorithms and updating of near-neighbour lists, should also be mentioned.

The Finite Element Method has a long tradition as a numerical tool for solving a large variety of Continuum Mechanics problems. However strong limitations appear when the method is used to capture free surfaces in the case of fluids, or large deformations in the case of solids. Both limitations emerge in the case of powder filling.

Very promising alternatives, in which the present work is framed, are the Particle Methods in which each particle is followed in a Lagrangian manner. The first ideas on this approach were proposed in the context of fluids [38-40], and lately generalized using the concepts of Delaunay triangulation and extended Delaunay tessellation; the result is the so-called Particle Finite Element Method (PFEM) [41]. This method can be understood as a natural extension of FEM to which an efficient remeshing tool is coupled.

In the present work a numerical model, based on a rate-dependent constitutive model, via a flow formulation, and in the framework of PFEM is proposed. This 
constitutive model with the corresponding characterization of the parameters is able to capture the two fundamental phenomena observed during the filling process: 1) the irreversibility of most of the deformation experienced by the material considered as a continuous medium (modelled by plastic irrecoverable deformations), and 2) the quick dissipation of the potential gravitatory energy of the granular system through the inter-particle friction processes (modelled by the plastic dissipation associated with the material model). The main ingredients of PFEM and the constitutive model will be described in next sections; however numerical implementation details are not considered in this work and will be described elsewhere.

\subsection{The particle finite element method}

The particle finite element methods emerged as a natural result of previous explorations in the context of the meshless methods. They can be characterized by the following ingredients: 1) the use of a Lagrangean format for describing the motion. A selected cloud of particles of infinitesimal size (material points) are tracked along the motion to describe the continuum medium properties evolution (position, displacement, velocities, strain, stresses, internal variables etc.). When necessary, the properties of the remaining particles of the continuum medium are obtained by interpolation of the properties at points of that cloud. 2) Numerical computations are done on the basis of a finite element mesh that is constructed at every tine step on the basis of the particle positions. Then, Delaunaly triangulations, allowing the construction of a finite element mesh for a given of nodes, emerge as a suitable meshing procedure recognition procedure to identify whe internal) boundary. The so-called alpha-shap strategy for this purpose. It essentially consists of eliminating those elements of

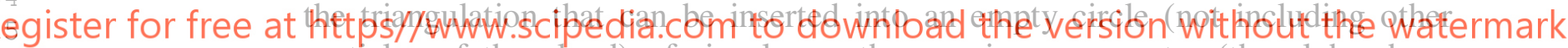
particles of the cloud) of size larger than a given parameter (the alpha-shape parameter). The nodes (particles) of those eliminated triangles can be then identified as the boundary particles. Large values of the alpha-shape parameter result in a boundary which is the convex hull of the cloud. Small values of the alpha-shape parameter return a boundary constituted of all the particles of the cloud. For a uniformly distributed cloud of particles (with typical separation $h$ ) alpha-shape values of 1.1-1.5 provide a good estimation of the actual boundary.

Fig. 11. Incremental non linear problem at time step $\left[t_{n}, t_{n+1}\right]$

The numerical procedure at a given time $t_{n+1}$ consists of the following stages (see Fig. 11): a) constructing a Delaunay triangulation on the basis of the particle positions at time $t_{n}$ (configuration $\Omega_{n}$ ), b) identification of the boundary of $\Omega_{n}$, and subsequent elimination of the external triangles, via alpha-shape methods, resulting in a triangle finite element mesh, c) solving the corresponding discrete incremental non-linear finite element problem, in a standard Lagrangean way referred to configuration $\Omega_{n}$, and obtaining all the required nodal (particle) variables of the problem: incremental displacements $\Delta \mathbf{u}_{n+1}$, velocities $\mathbf{v}_{n+1}$, accelerations $\mathbf{a}_{n+1}$, stresses $\boldsymbol{\sigma}_{n+1}$, internal variables $q_{n+1}$ etc., d) updating the 


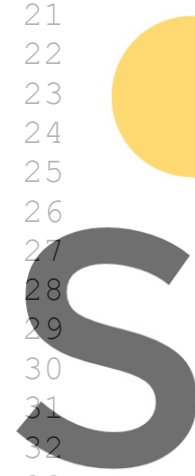

33

\section{Be}

positions of the particles according to the displacements of the previous time step resulting in the configuration $\Omega_{n+1}$.

\subsection{Constitutive model for the powder}

The constitutive model formulation is based on the assumption that the powder can be modeled as a continuous medium that can be continually sub-divided into infinitesimal small elements with properties being those of the bulk material. During filling the total strains are so large that the elastic deformation can be considered as negligible versus the plastic or viscoplastic strains, and the state of deformation can be considered as given by a constitutive law which defines the strain rate as a non-zero function of stresses. In such cases, taking into account the similarity of behavior of powder under continuous flow regime to that of a viscous fluid, a kind of compressible non-Newtonian viscous fluid model is assumed. Thus, the stresses developed can be related to the deformation rate in the powder, which in turn can be related to the nodal positions and velocity. This procedure is known as the 'flow approach', and was first presented in the work of Goon et al. [42]; Zienkiewicz and Godbole [43] gave a more general solution for viscoplastic materials. The powder filling is simulated by adopting constitutive relations developed for compaction processes $[6,12,44]$, in the frame of soil constitutive models, but with a complete reinterpretation of the parameters. All the governing equations will be described next.

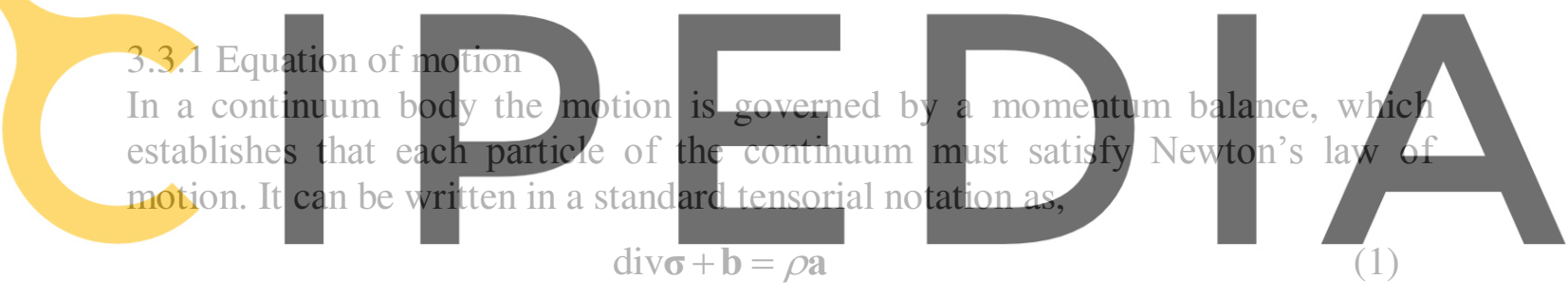

$$
\operatorname{div} \sigma+\mathbf{b}=\rho \mathbf{a}
$$

where $\sigma$ is the Cauchy stress tensor, $\mathbf{b}$ is the body force vector, a is the acceleration and $\rho$ is the density of the material. For the other stages of the compaction process, such as powder transfer and pressing it is usual to neglect acceleration effects, however during powder filling these will be of importance.

\subsubsection{Strain rate relation}

The strain rate experienced in the continuum body are defined by the spatial derivatives of velocity an can be written as,

$$
\mathbf{d}=\frac{1}{2}\left[(\nabla \mathbf{v})+(\nabla \mathbf{v})^{T}\right]
$$

where $\mathbf{d}$ is the strain rate tensor and $\mathbf{v}$ is the velocity

\subsubsection{Stress - strain rate relations}

In the general setting of compressible viscous fluid, the constitutive relation can be written in the form

$$
\boldsymbol{\sigma}=p \mathbf{I}+2 \mu \mathbf{d}
$$




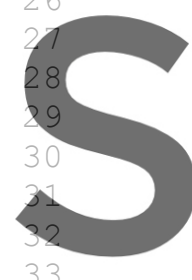

in which devo is the deviatoric stress tensor. In the context of visco-plasticity (Perzyna description [50]) the last expression can be written with some degree of generality as

$$
\mathbf{d}=\frac{1}{\bar{\mu}}\langle F\rangle \frac{\partial G}{\partial \boldsymbol{\sigma}}
$$

where $\bar{\mu}$ is a constant 'pseudo-viscosity', $F(\sigma)=0$ represents the plastic yield condition and $G$ stands for the plastic potential. The angled bracket in (5) represents the Macaulay bracket that takes the value of the argument when positive and is zero otherwise. This term ensures no plastic flow when stresses are below yield

$$
\langle F\rangle=F \text { if } F>0 \text { and }\langle F\rangle=0 \text { if } F \leq 0
$$

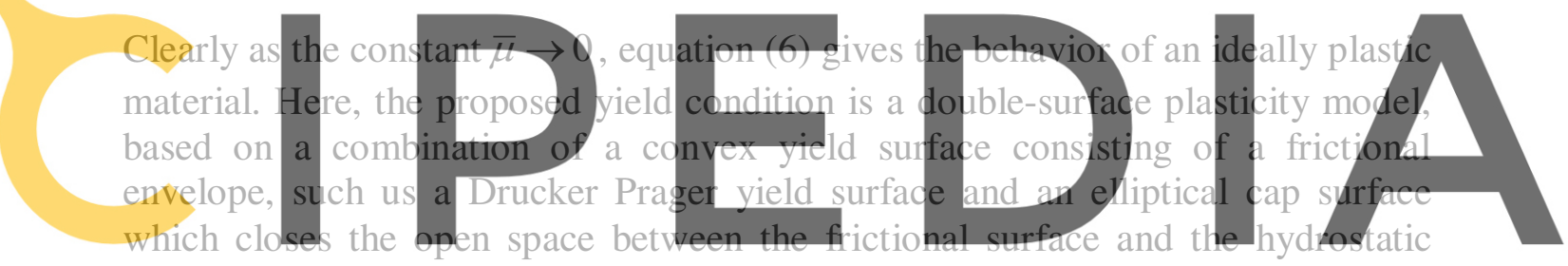
axis (figure 12).

\section{gister for free at https//www.scipedia.com to download the version without the watermark Fig 12. Yield surface: centred elliptical cap and Drucker Prager line}

The yield cap expands in the stress space according to the evolution of the material density. The functional forms for both surfaces may be quite general and would allow for the fitting of a wide range of material properties. The functional form of the Drucker Prager surface is

$$
F_{1}=\sqrt{\frac{3}{2}}\|\operatorname{dev} \boldsymbol{\tau}\|+b_{1} p-b_{2} .
$$

The partial sum of the first two terms defines the pressure-dependent equivalent stress. While in the classical literature $b_{2}$ is the yield stress under pure shear, here it is reinterpreted as the cohesion of the powder material. The coefficient $b_{1}$ is a positive parameter that controls the influence of the pressure on the yield limit, which is understood as the internal friction coefficient of the continuous flow regimen. A non-associated flow rule is assumed on the Drucker-Prager surface and consists of a pure deviatoric strain-rate (incompressible) and an associated flow rule is assumed on the cap. The flow vector, in the case of the Drucker Prager surface, can be written as 


$$
\left(\frac{\partial G}{\partial \boldsymbol{\sigma}}\right)=\operatorname{dev} \boldsymbol{\sigma} .
$$

where $G$ represents the plastic potential. When flow occurs, $F_{1} \geq 0$ and expressions (4) and (5) can be identified, and then using (7) and (8) we can obtain the viscosity $\mu$ as the solution of the following quadratic expression

$$
6 \dot{\bar{\varepsilon}} \mu^{2}+2 \mu\left(b_{1} p-b_{2}\right)-\bar{\mu}=0
$$

where $\dot{\bar{\varepsilon}}=\sqrt{\frac{2}{3}\|\operatorname{devd}\|}$ is the equivalent strain rate. In the case of ideal plasticity, when $\bar{\mu} \rightarrow 0$, the non-linear (pressure dependent) viscosity can be simply written as

$$
\mu=\frac{b_{2}-b_{1} p}{3 \dot{\bar{\varepsilon}}}
$$

\section{Using both the constitutive relation (3) and the viscosity (11), an expression for the deviatoric part of the stresses, in terms of the strain rate, can be fully obtained. In the case of fluids, or in general for incompressible materials, the mean stress is obtained from of the incompressibility condition. Here a compressibility law is adopted and the mean stress is expressed as}
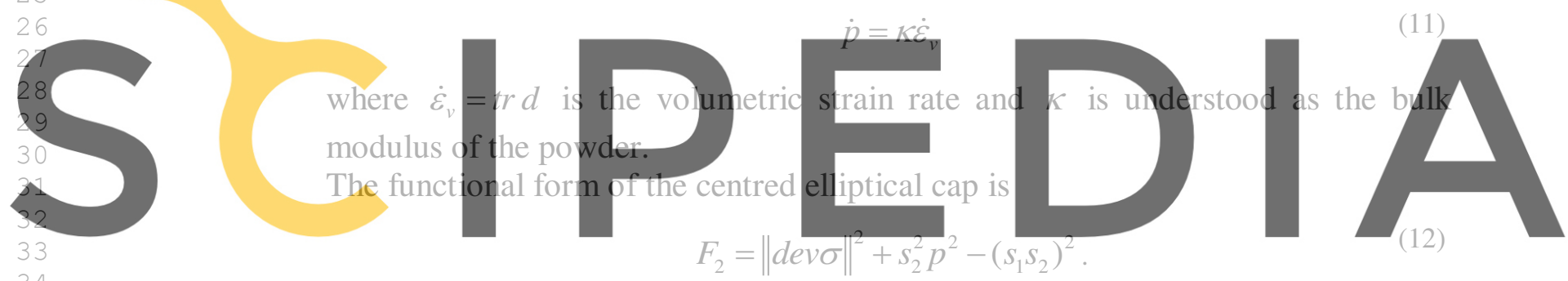

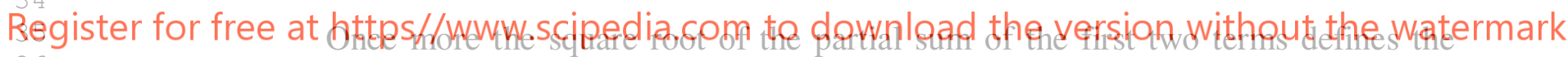
pressure-dependent equivalent stress. Parameters $S_{1}$ and $s_{2}$, depending on the density, determine the size and shape of the ellipse in terms of the radii $r_{1}$ and $r_{2}$ as

$$
s_{1}(\rho)=r_{1}(\rho) \quad s_{2}(\rho)=\frac{r_{2}(\rho)}{r_{1}(\rho)} .
$$

These parameters can be characterized studying the behavior of the powder, under compression, in the range of low densities; the range going from the apparent density to the tap density $[12,44]$. In this case an associated flow rule is utilized, and then the yield surface and the plastic potential surface are coincident. Under these circumstances the vector flow can be written as

$$
\frac{\partial F_{2}}{\partial \sigma}=2 \mu\left(\operatorname{dev} \sigma+\frac{1}{3} s_{2}^{2} p I\right) .
$$

In case of $F_{2} \geq 0$ and when ideal plasticity is supposed the non linear viscosity can be written as

$$
\mu=\frac{s_{1} s_{2}^{2}}{2 \sqrt{\frac{3}{2} s_{2}^{2} \dot{\bar{\varepsilon}}^{2}+\left(\dot{\varepsilon}_{v}\right)^{2}}} .
$$



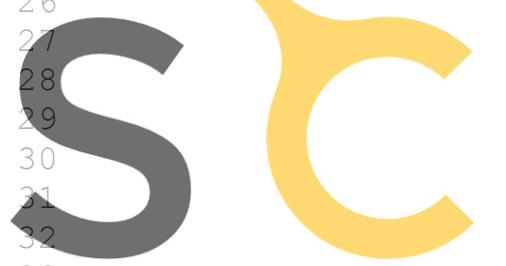

Equations in Table

Table 2. Constitutive

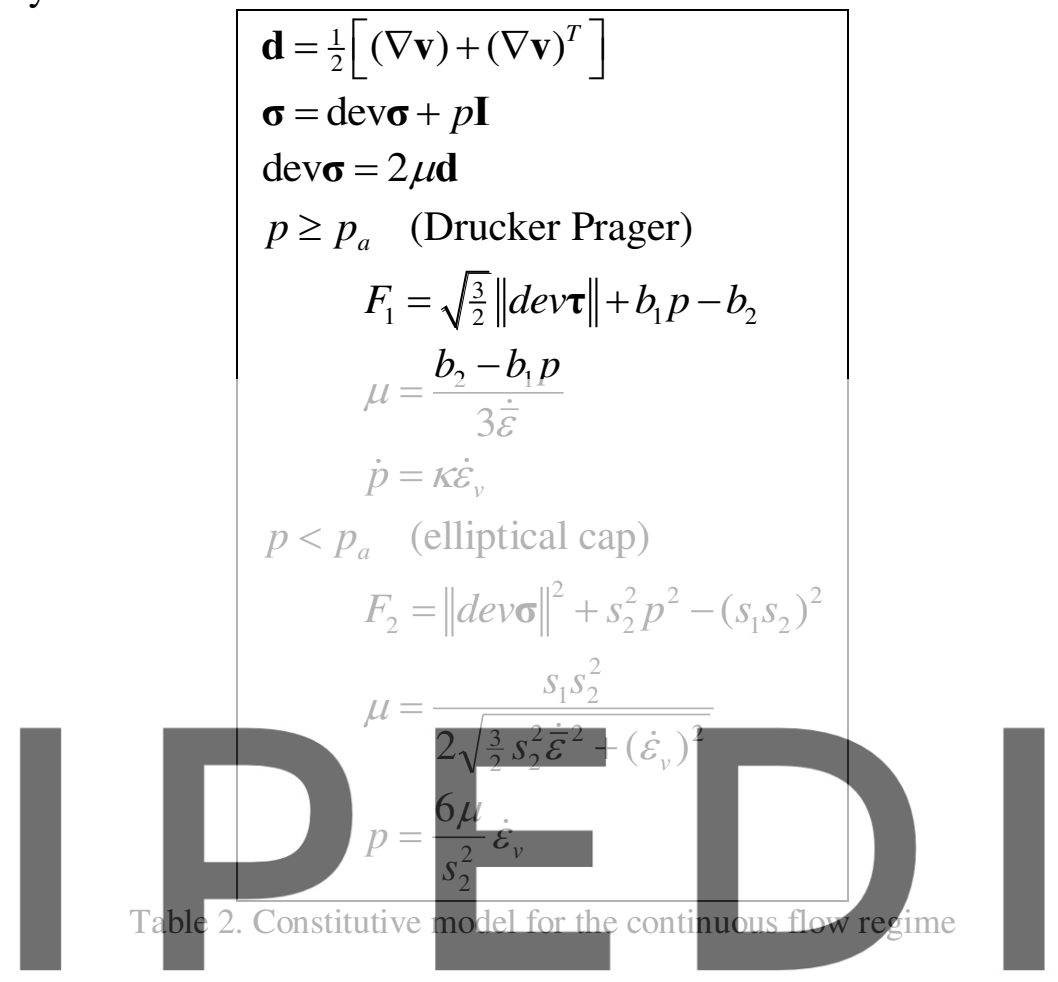

$$
p=\frac{6 \mu}{s_{2}^{2}} \dot{\varepsilon}_{v}
$$

A summary of the constitutive model is contained in BOX 1 .

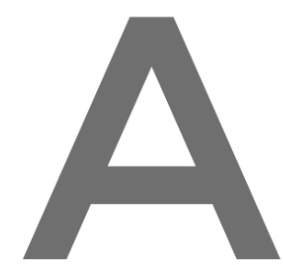

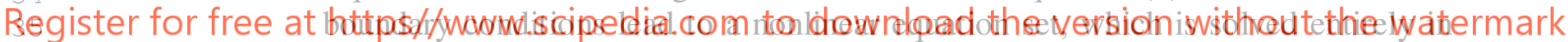
the context of PFEM. All numerical aspects concerning discretization, resolution and implementation of the equations are described elsewhere [51].

\section{Numerical and experimental results}

In this section we present the numerical and experimental results of two examples concerning the filling of a single die cavity subjected to a continuous flow regime. The first example focuses on the material characterization of the internal friction parameter of the constitutive model. It is achieved studying the generated flow pattern inside the shoe. The second example concentrates on the analysis of the whole behavior of the powder at the time it is delivered into the die. Due to the thickness of the tools (shoe and die) the plain strain hypothesis can be considered, consequently the numerical simulation can be done in 2D. The considered particles and initial position of the tools, for both experiments, are shown in figures 12,13 . They consist of 1250 and 4500 particles, respectively, to represent the powder material. The powder behavior is simulated by means of the constitutive model described above. The apparent density is $1.5 \mathrm{~g} \mathrm{~cm}^{-3}$ and with no less of generality, rigid tools are supposed for the shoe and die. 


\subsection{Characterization of the internal friction}

The constitutive model described in Section 3 involves several material properties that have to be evaluated for every powder mixture to be considered in the simulations. This example focuses on the characterization of the material parameters $b_{1}$ and $b_{2}$ of the Drucker Prager surface (7); the cohesion and the internal friction coefficient (angle) both during the continuous flow regimen.

In this case, in which the powder behaves as a frictional material, the cohesion is closely related with the tensile strength that is negligible, therefore a very small number for the cohesion is used to avoid numerical indetermination. In our case the value $b_{2}=1.0 \times 10^{-2} \mathrm{~Pa}$, was used.

Several devices for studying the important characteristics of powder flow under low-pressure systems have been developed [46]. These apparatus are used to study the effect of vibration, flowagents and aeration on the low-pressure rheology of powders. When the powder is allowed to flow out of a container different angles can be distinguished (e.g. angle of repose, false angle of repose[46], angle of sliding) showing the powder behavior complexity. It is not so clear which of these parameters, or a combination of them, fit well the internal friction angle, $b_{1}$ of the Drucker Prager surface (7). For this reason we focus on the behavior of the powder while it is delivered into the die.

Experiments were carried out to estimate this parameter as follows. Details of the movement are recorded using a high-speed video system attached to the horizontal shoe, while fine sand is delivered into the die at a speed of $100 \mathrm{~mm} / \mathrm{s}$. The sand, coloured alternatively light and dark, is initially placed in a chessboardlike arrangement.

Fig. 13. Comparisons between the flow of sand in the shoe recorded by a high speed video system attached to the shoe $(\mathrm{a}-\mathrm{d})$, and numerical results obtained using PFEM (e h).

Figure 13 shows a typical flow pattern during the filling; experimental results are grouped on the left column while numerical ones are on the right column. By observing that the top surface of the powder in the shoe was essentially unaltered when the shoe accelerated from rest, it was presumed that inertia effects were negligible here.

During the first steps when the shoe starts traversing over the die cavity, the first light square of grains detaches easily and falls freely into the die. This falling process continues along the rest of the column and progressively affects adjacent columns. Afterwards a continuous flow regime is completely developed and a nearly constant angle of sliding is clearly identified. It is a crucial feature to be exploited for characterization of the internal friction angle.

Fig. 14. Variation of the powder surface profiles with time 
Figure 14 shows how the external profile of the pouring powder evolves with time. It can be observed that the profiles maintain approximately the constant slope meaning that a steady state has been reached.

The parameter of the internal friction $b_{1}$ determines the profile of the surface. Different simulation profiles, corresponding to different values of $b_{1}$ at $t=0.52 \mathrm{~s}$ are shown in Figure 15. As the parameter $b_{1}$ increases, the influence of the internal friction becomes more pronounced. For small values of $b_{1}$ the material behaves like a fluid while for large values of $b_{1}$ the powder recover the granular behavior. This strong dependence on $b_{1}$ demonstrates the important effect of the internal friction.

The characterization of $b_{1}$ results from the comparison of the experimental external profiles (Figure 14) and the simulation profiles (Figure 15). The value of $b_{1}$ reproducing better the experimental behavior, $b_{1}=1.2$, has been used for the numerical simulation.

Fig. 15. Simulated surface powder profiles for different values of the internal friction parameter at $t=0.52 \mathrm{~s}$

\subsection{Representative simulation of the filling of a single cavity}

Figure 16 shows a typical flow pattern during the filling of a single die cavity, in which fine sand, displayed in five coloured horizontal layers, is delivered into a simple die by a moving horizontal shoe at a speed of $100 \mathrm{~mm} / \mathrm{s}$. As the shoe traverses over the die cavity, three flow stages occur successively. The first of these is the development of the continuous regimen in which a nearly constant angle of sliding is clearly identified, as was pointed out in section 4.1. The second is the free-falling powder and the third is the rearrangement of the particles as they contact the die and settled down.

In the simulation of the process, a one second time duration divided into 6500 steps is considered. With the aim of obtaining an initial consistent mean stress an extra time interval is included at the beginning in which the shoe is at rest, the gravity is switched on, and elastic model with Young's modulus of $=0.1 \mathrm{Mpa}$ and Poisson's ratio of 0.3 is supposed. Similar elastic regularization is also considered when the velocity is so small that the constitutive flow model is undetermined and leads to numerical difficulties. This regularization can be also understood as imposing an arbitrary large viscosity as a cut-off value. Once the shoe begins to move and the particles on the bottom lose the contact, the velocity increases, the pressure decreases, and the flow mechanisms are activated (Figure 13a). This continuous flow is governed by the Drucker Prager surface. Afterwards the particles fall freely into the die due to the action of the gravity. This movement is conducted by the motion equation. When the bottom of the die is contacted by the powder, the third stage of the flow is initiated (Figures 13b). During this stage millions of particles collide with the walls of the die and with each other, the kinetic energy of the flowing granular material is dissipated through the binary collisions of particles at the micro-scale $[13 \mathrm{c}]$. In terms of the proposed continuum approach, 
this dissipation mainly results from the plastic deformation induced by the elliptical cap model, for which the aspect-ratio coefficient is set to $s_{2}=1$ and the compressibility curve is set to $s_{1}(\rho)=0.007482 \rho^{5.5}$ where $\rho$ is the material density in $\mathrm{g}^{-\mathrm{cm}^{-3}}$. The sequence of images presented in figure 13e-h show the major features described before as flow stages. These features are in broad agreement with the experimental observations. The deformation pattern can also be clearly identified studying the coloured layers of the powder. They transform from initially horizontal layers to roughly vertical ones. This pattern can also be recognized in the numerical results.

Fig. 16. Typical flow pattern for fine sand during the filling of a single die cavity. The experimental results are shown on the left and the numerical simulations are depicted on the right.

\title{
5. Conclusions
}

The experiments have shown the existence of three flow regimes: continuous, transitory and discrete, which have been identified in terms of the particle size, the morphology and the speed of the shoe. At the continuous regime the powder flows in a progressive manner while at the discrete one some perturbations appear as a consequence of a shear band formation that derives in discrete avalanches. Equivalent perturbations are also found when the mass flow rate is considered [46], which characterizes the flowability of the powder and measures its efficiency and speed during a filling process.

The numerical simulation results obtained in the context of the particle finite element method were able to qualitatively capture experimentally observed flow regimes. The constitutive model requires mainly the characterization of the internal friction angle and the compressibility curve at the range of low densities. Other numerical simulation methods such as DEM need to calibrate a large number of parameters which are mainly focused on the correct computation of contact and friction forces between particles. By using the constitutive method described in this paper (continuous approach) a single parameter, the internal friction, is sufficient. The problem of element distortion, hindering the convergence of the solution found in FEM for large deformations have been avoided by a code that provides a continuous remeshing.

\author{
Acknowdlegments \\ The authors acknowledge the Spanish Ministry of Education and Science for \\ grants DPI 2003-00629 and DPI 2004-07666-C02-01
}




\section{References}

[1] Zenger D.C., Cai H.H.: Handbook of: the common cracks in P/M compacts, Metal Powder Industries Federation (1997)

[2] Weber, G.G. and Brown S. Simulation of the Compaction of Powder Components. Advances in Powder Metallurgy, MPIF/APMI, Princeton, New Jersey 08540, 1989.

[3] Brekelmans W. A. M., Janssen J. D. and Van De Ven A.A.F. Int. J. Num. Methods. Eng. 31, 509-524, 1991.

[4] Gethin D.T, Tran., D.V., Lewis, R.W. and Ariffin, A.K. (1994) An investigation of powder compaction processes. Int. Jou. Powder Metall., 30, pp. 385-398.

[5] Haggblad H.A. and Oldenburg, M. (1994) Modelling and simulation of metal powder die pressing with use of explicit time integration. Model. Simul. Muter.

Sci. Eng., 2, pp. 893-911

[6] J. Oliver, S. Oller, J. C. Cante: Int. J. Solids and Struct, 33, 3161-3178, 1996

[7] Lewis R.W., Khoei A.R. (1998) Numerical modelling of large deformation in metal powder forming. Cornput. Meth. Appl. Mech. Eng., 159, pp. 291-328.

[8] Khoei A.R and Lewis R.W.: Int. J. Numer. Methods Eng. 1999, 45, 801-820

[9] PM Modnet Computer Modelling Group: Powder Metall, 42, No. 4, 301-311, 1999

[10] PM Modnet Research Group: Powder Metall., 2002, 45, 335-344

[11] Wu Chuan-Yu, Cocks A.C.F., Gillia O.T. Thompson D.A., Experimental and numerical investigations of powder transfer Powder Technology, 138, 216-228, 2003

[12] Cante J.C., Oliver J., Gonzalez C., Calero J.A., Benítez F. On the Numerical Simulation of Powder Compaction Processes: Powder Transfer Modelling and Characterization, Powder Metallurgy, Vol. 48,1, 85-92, 2005

[13]Wu C.-Y, Cocks A.C.F., Gillia O.T. Experimental and numerical investigations of die filling and powder transfer, Advances in Powder Metallurgy and Particulate Materials 4, 258-272, 2002

[14] Wu C.-Y and Cocks A.C.F., Flow behaviour of powders during die filling, Powder Metallurgy, Vol. 47, 2, 127- 136, 2004

[15] Coube O., Cocks A.C.F. and Wu C.-Y Experimental and numerical study of die filling, powder transfer and die compaction, Powder Metallurgy, Vol. 48, 1, 68-76, 2005

[16] Schneider L.C.R., Cocks A.C.F., and Apostolopoulos A., Comparison of filling behaviour of metallic, ceramic, hardmetal and magnetic powders, Powder Metallurgy, Vol. 48, 1, 77-84, 2005

[17] Rosato, A. D., Prinz, F., Strandburg, K., Swendsen, R.: Monte Carlo simulation of particulate matter segregation, Powder Technol. 49, 59 (1986)

[18] Rosato, A. D., Strandburg, K. J., Prinz, F., Swendsen, R. H.: Why the Brazil Nuts are on top: Size segregation of particulate matter by shaking, Phys. Rev. Lett. 58, 1038 (1987)

[19] Baxter, G. W., Behringer, R. P.: Cellular automata models of granular flow, Phys.Rev. A 42, 1017 (1990)

[20] Baxter, G. W., Behringer, R. P.: Cellular automata models for the flow of granular materials, Physica D 51, 465 (1991)

[21] Caram, H., Hong, D. C.: Random-walk approach to granular flows, Phys.

Rev. Lett. 67, 828 (1991)

[22] Caram, H., Hong, D. C.: Diffusing void model for granular flow, Mod. Phys.Lett. B, 6, 761 (1992) 
[23] Meakin, P., Jullien, R.: Simple models for two and three dimensional particle size segregation, Physica A 180, 1 (1992)

[24] Barker, G. C., Mehta, A., Grimson, M. J.: Comment on "Three-dimensional model for particle size segregation by haking”, Phys. Rev. Lett. 70, 2194 (1993)

[25] Luding, S. Molecular Dynamics Simulations of Granular Materials in: The Physics of Granular Media, H. Hinrichsen and D. Wolf, eds., Wiley-VCH, Weinheim, 2004 (ISBN 3-527-40373-6), pp. 299-324 [26] Allen, P. Introduction to Molecular Dynamics Simulation, Computational Soft Matter: From Synthetic Polymers to Proteins, N. Attig, K. Binder, H. Grubmüller, Kurt Kremer (Eds.), John von Neumann Ins. for Comp., Jülich, NIC Series, Vol. 23, ISBN 3-00-012641-4, pp. 1-28, 2004.

[27] Cundall, P. A. and O. D. L. Strack (1979). A discrete numerical model for granular assemblies. Géotechnique 29(1), 47-65.

[28] Idelsohn, S.R.,Onate, E.,Del Pin, F.: A Lagrangian meshless finite element method

applied to fluid-structure interaction problems. Computers \& Structures. 81, 655671, 2003.

[29] Idelsohn, S.R.,Onate, E.,Del Pin, F.: The particle finite element method: a powerful tool to solve incompressible flows with free-surfaces and breaking waves. International Journal for Numerical Methods in Engineering. 61, 964989, 2004.

[30] Ristow, G. H. : Flow properties of granular materials in three-dimensional geometries. PhD Thesis. Philipps-Universität Marburg. (1998)

[31] Beverloo, W.A., Leniger, H.A., Van De Velde, J. : The flow of granular solids through orifices, Chemical Engineering Science 15 260-269 (1961)

[32] Isturiz, A., Riera, M.D., Prado, J.M. : Experimental study of die filling in powder

Metallurgy. Rev.Metal. Madrid Vol. Extr. 181-186 (2005)

[33] Van-Burkalow, A.: Bull. Geol. Soc. Am., 56669 (1945)

[34] Rajchenbach, J.: Flow in Powders: From discrete avalanches regime to continuous regime, Phys. Rev. Lett., 65 2221-2225 (1990)

[35] Rudnicki, J. W., Rice, J. R.: J. Mech. Phys. Solids 23371 (1975)

[36] Bardet, J. P., Proubet, J.: J Eng. Mech. 118397 (1992)

[37] Herrmann, H.J.: Structures in deformed granular packings, Granular Matter 3 15-18 (2001).

[38] Belytschko, T., Liu, Y. and Gu. L. Element free Galerkin methods, International Journal for Numerical Methods in Engineering, 37, (1994), 229-256

[39]De S. and Bathe, K.J. The method of finite spheres with improved numerical integration, Computer \& Structures, Vol.79, (2001), 2183-2196.

[40] Oñate, E., Idelsohn, S.R. Zienkiewicz O.C. and Taylor, R.L. A finite point method in computational mechanics. Applications to convective transport and fluid flow, International Journal for Numerical Methods in Engineering, 39(22), (1996a), 3839-3886.

[41] S.R. Idelsohn, E. Oñate, F. Del Pin, The particle finite element method: a powerful tool to solve incomprensible flows with free surfaces and breaking waves, Int. J. Num. Methods Engrg. 61, (2004), 964-989

[42] Goon, G.Y., Poluchin P.I., Poluchin W.P., Prudcowsky B.A., The plastic deformation of metals, Metallurgica, in Russian (1968)

[43] Zienkiewicz O.C., Godbole P.N. Flow of plastic and visco-plastic solids with special referente to extrusion and forming processes, Inter. J. for Num. Meth in 
Eng, Vol 8, 3-16 (1974)

[44] Jinka, A.G., Lewis R.W., Gethin D.T., Finite element simulation of powder compaction via the flow formulation, Proceedings of the 1992 powder metallurgy World congress, p2 (92-V2) pp 123-144

[45] Schneider L.C.R. and Cocks A.C.F. Development and test results of a low pressure instrumented die, to appear in Powder Metallurgy

[46] Kaye B.H., Powder mixing, Powder technology series, Chapman \& Hall, 1997

[47] Istúriz A. Estudio experimental del llenado de moldes pulvimetalúrgicos, $\mathrm{PhD}$ thesis, 2006

[48] E. Hjortsberg and B. Bergquist, Filling induced density variations in metal powder, Powder Metallurgy, 45, 2, 146-153, 2002

[49] Calvo N.,Idelsohn S.R.,Onate E. The extended Delaunany tessellation. Engineering Computations. 20, 583-600, 2003.

[50] Jacob Lubliner, Plasticity Theory, Macmillan Publishing, New York (1990)

[51] J.C. Cante, J. Oliver, R. Weyler, J. Hernandez, Numerical Modelling Of Granular Material Flow by The Particle Finite Element Method (In preparation). 
Table I. Physical and morphological properties of the powders

\begin{tabular}{|c|c|c|c|c|c|}
\hline Powder & Coarse Sand & $\begin{array}{c}\text { Irregular } \\
\text { copper }\end{array}$ & $\begin{array}{c}\text { Spheroidal } \\
\text { copper }\end{array}$ & Irregular iron & Fine stone \\
\hline $\begin{array}{c}\text { Density of the bulk } \\
\text { material } \\
{\left[\mathrm{Mg} / \mathrm{m}^{3}\right]}\end{array}$ & $2.43 \pm 0.01$ & $8.96 \pm 0.01$ & $8.96 \pm 0.01$ & $7.86 \pm 0.01$ & $2.54 \pm 0.01$ \\
\hline $\begin{array}{c}\text { Apparent density } \\
{\left[\mathrm{Mg} / \mathrm{m}^{3]}\right.}\end{array}$ & $1.58 \pm 0.01$ & $4.7 \pm 0.01$ & $5.1 \pm 0.01$ & $3.05 \pm 0.05$ & $1.61 \pm 0.05$ \\
\hline $\begin{array}{c}\text { Diameter } \\
\left(\mathrm{d}_{\mathrm{P}} \pm \Delta \mathrm{d}_{\mathrm{p}}\right)[\mathrm{mm}]\end{array}$ & $0.793 \pm 0.24$ & $25.3 \pm 18.4$ & $66.24 \pm 18.49$ & $0.233 \pm 0.06$ & $3665 \pm 0.06$ \\
\hline Morphology & Faceted & Irregular & Spheroidal & Irregular & Irregular \\
\hline
\end{tabular}

$\Delta \mathrm{d}_{\mathrm{p}}:$ Standard deviation 


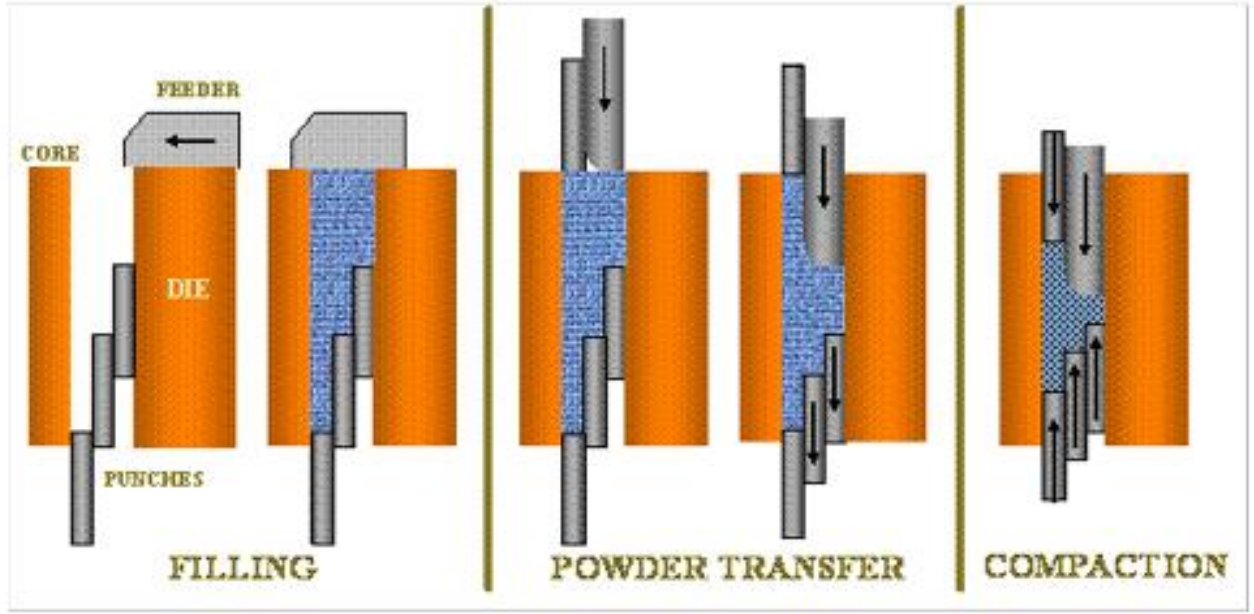

Fig.1 


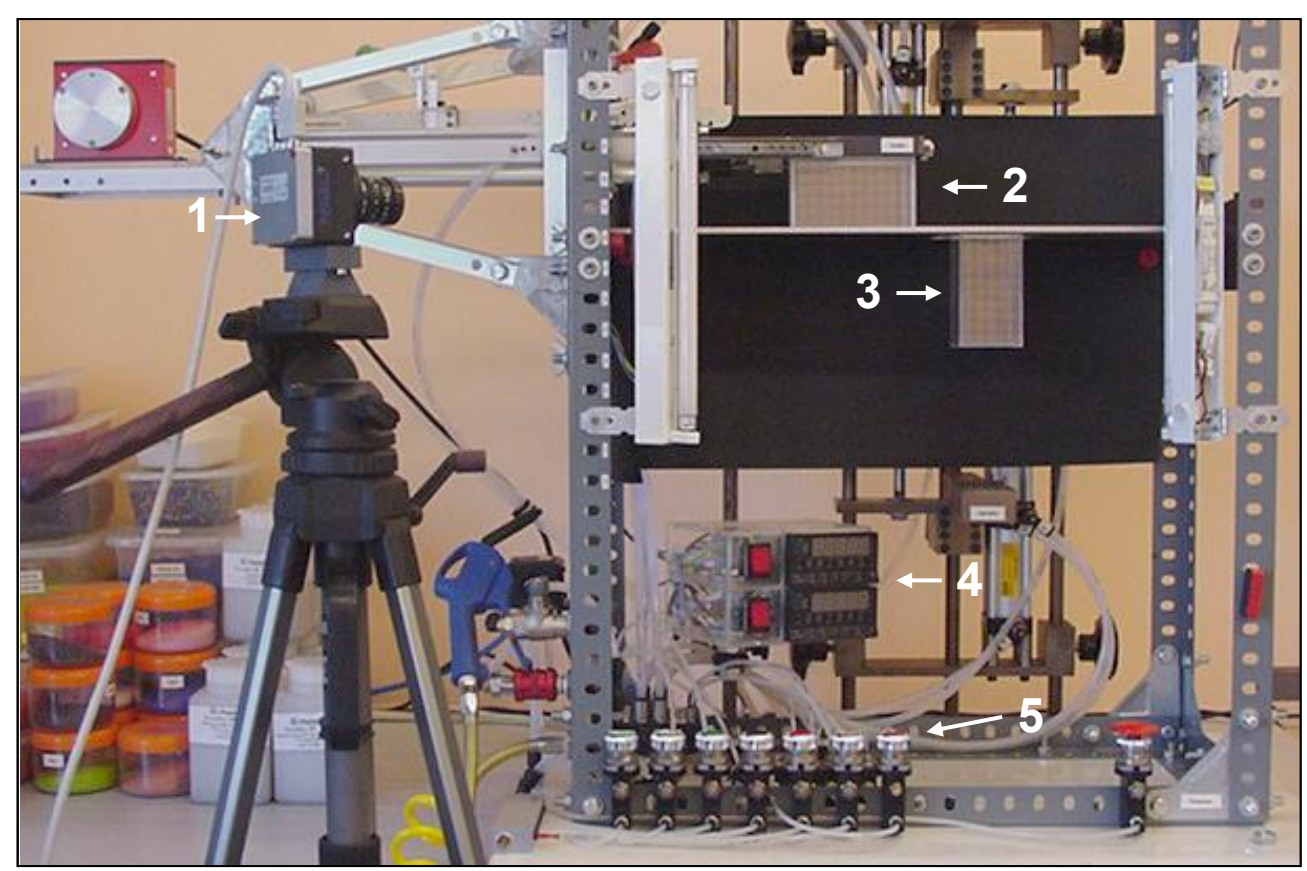

Fig.2 


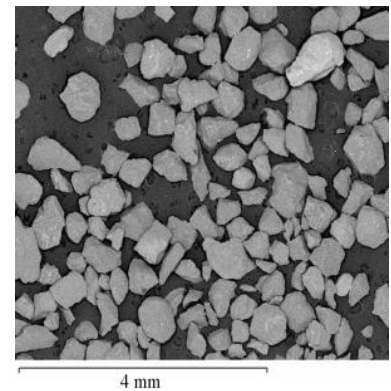

a) Coarse sand.

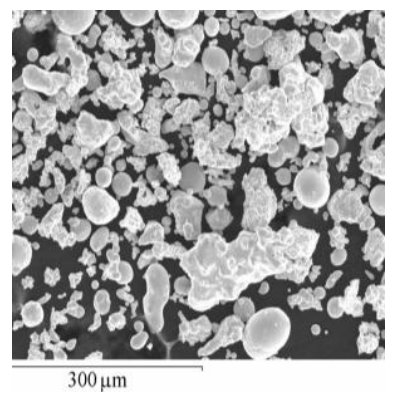

b) Irregular copper

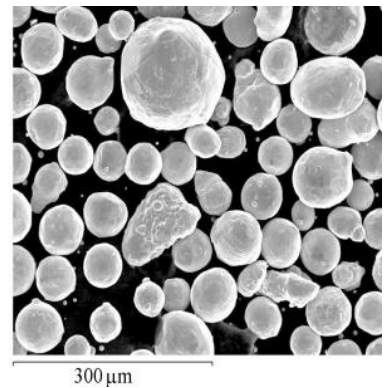

c) Spheroidal copper

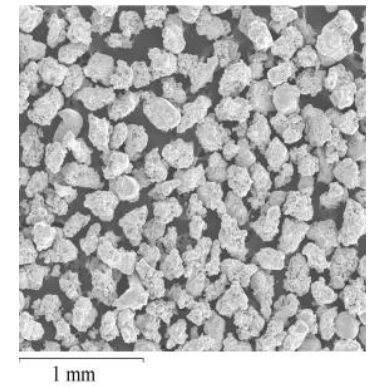

d) Irregular iron

Fig.3 


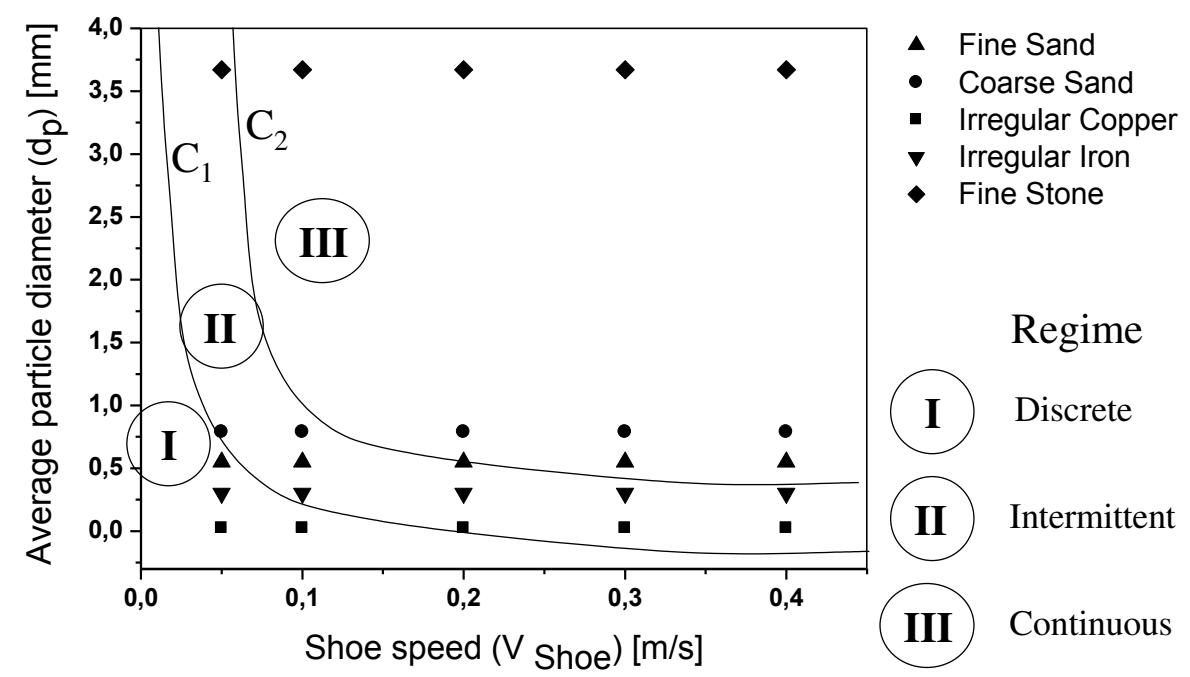

Fig.4 


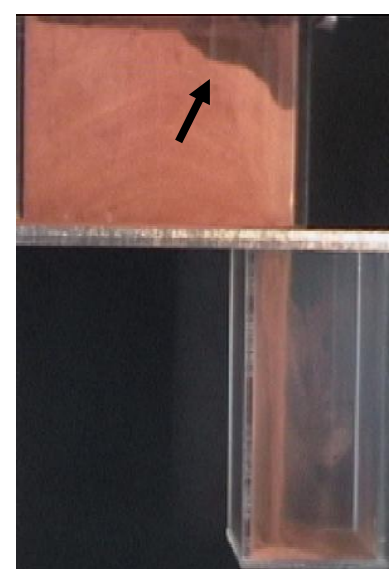

a) $\mathrm{t}=0.28 \mathrm{~s}$

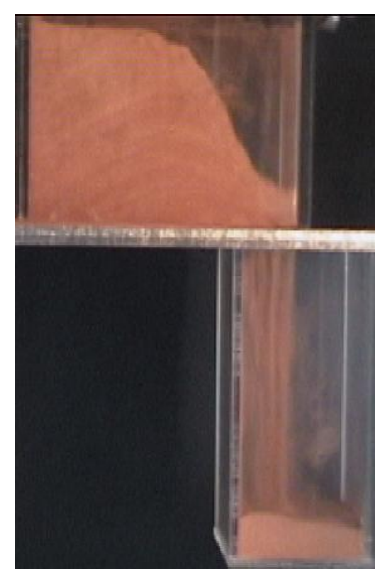

b) $\mathrm{t}=0.4 \mathrm{~s}$

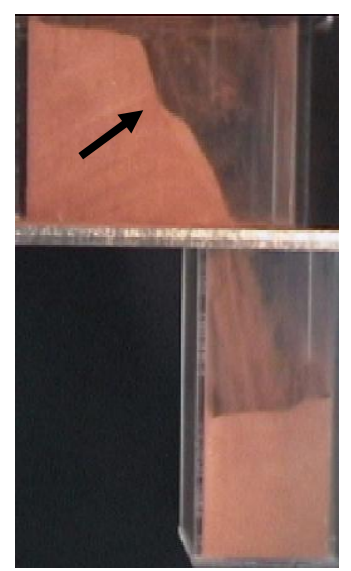

c) $t=0.64 \mathrm{~s}$

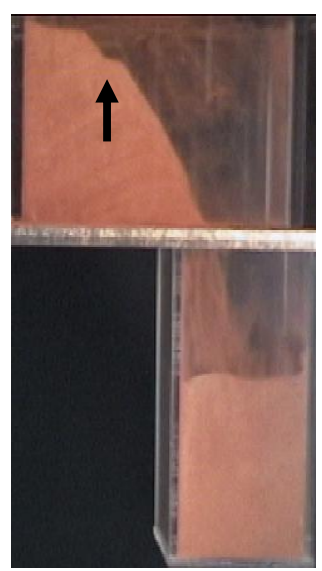

d) $\mathrm{t}=0.8 \mathrm{~s}$

Fig.5 


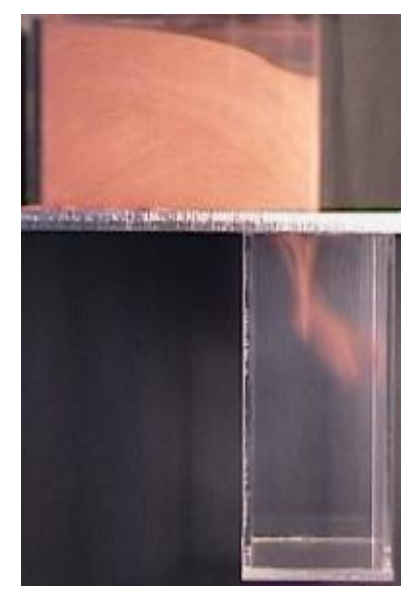

a) $t=0.08 \mathrm{~s}$

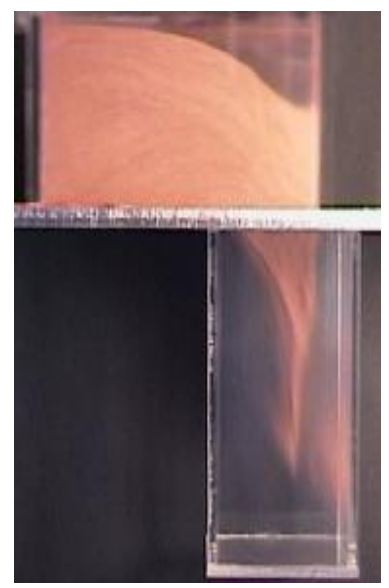

b) $t=0.12 \mathrm{~s}$

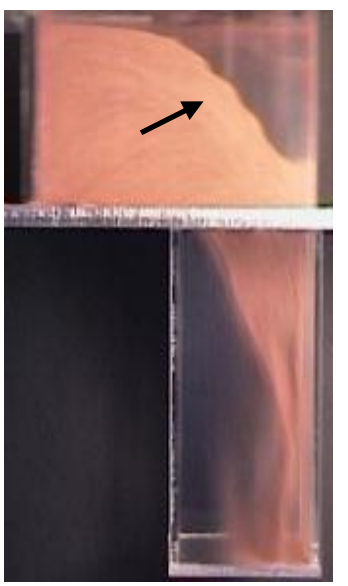

c) $t=0.16 \mathrm{~s}$

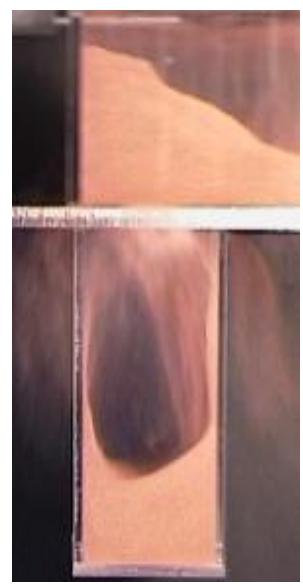

d) $t=0.24 \mathrm{~s}$

Fig.6 


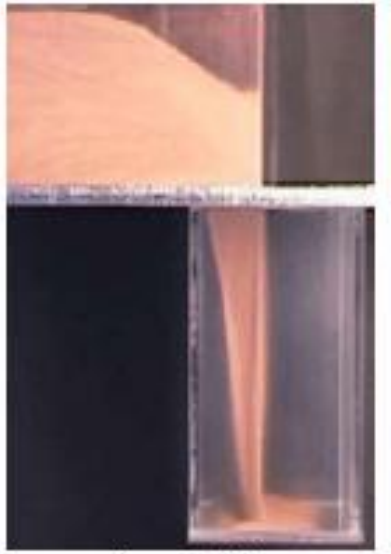

a) $\mathrm{t}_{\mathrm{f}}=0,20 \mathrm{~s}$
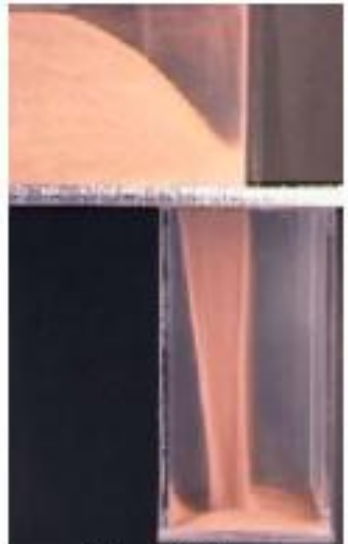

b) $t_{f}=0,25 \mathrm{~s}$

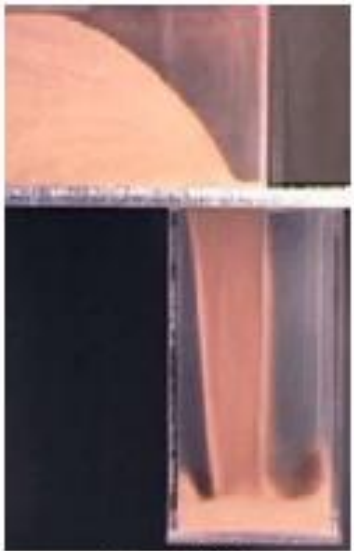

c) $\mathrm{t}_{\mathrm{f}}=0,30 \mathrm{~s}$

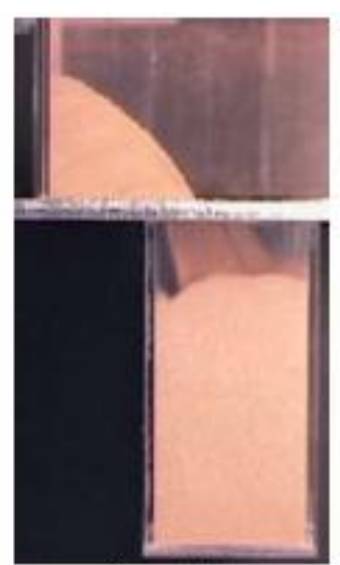

d) $t_{l}=0,7 \mathrm{~s}$

Fig.7 


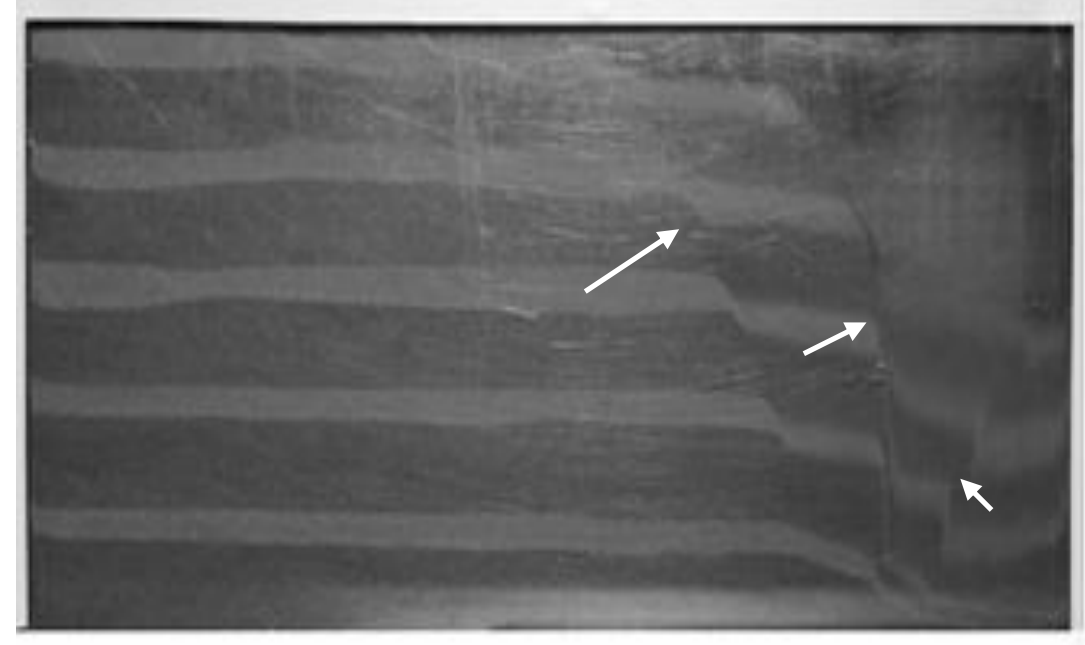

Fig. 8 


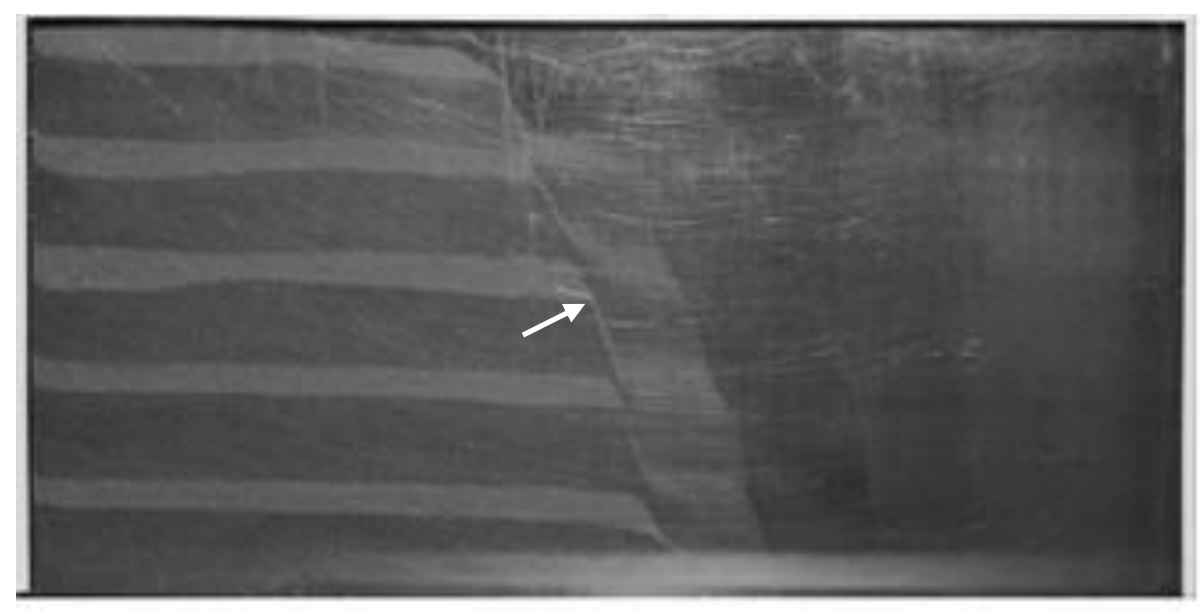

Fig.9 


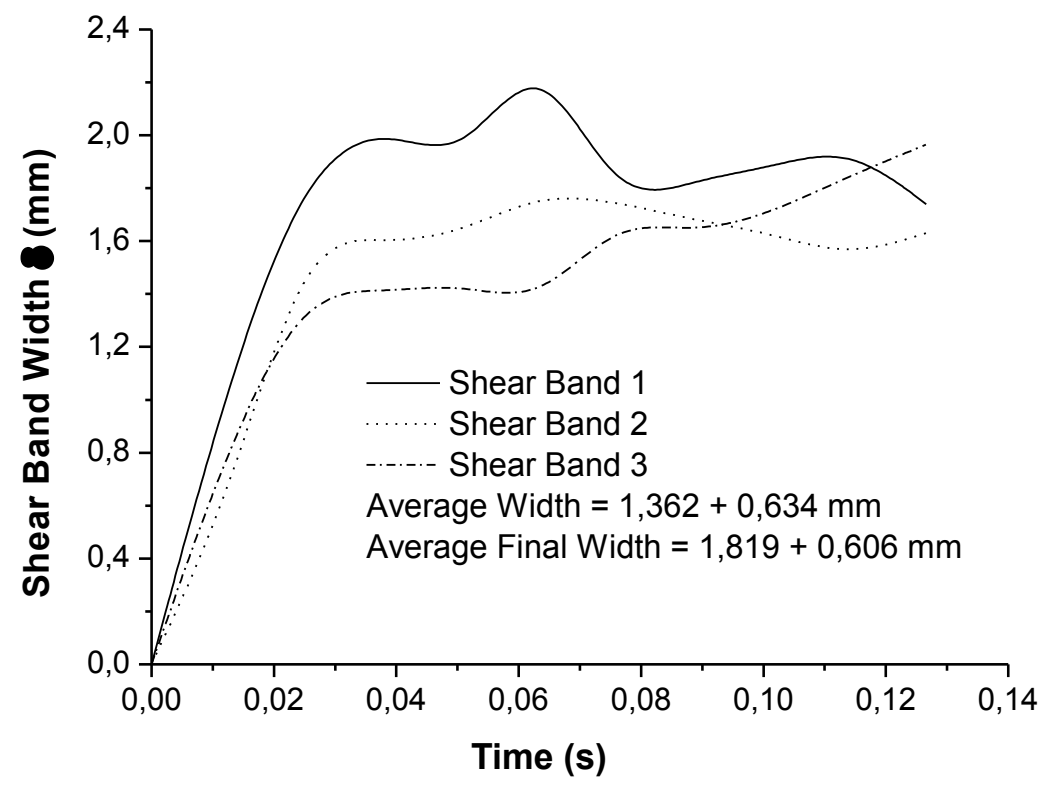

Fig.10 


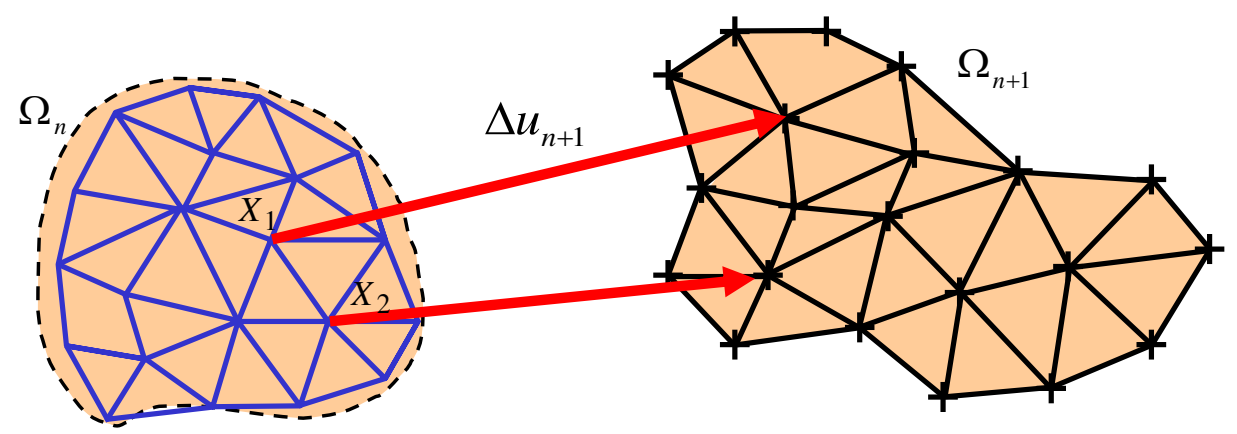

Fig. 11 


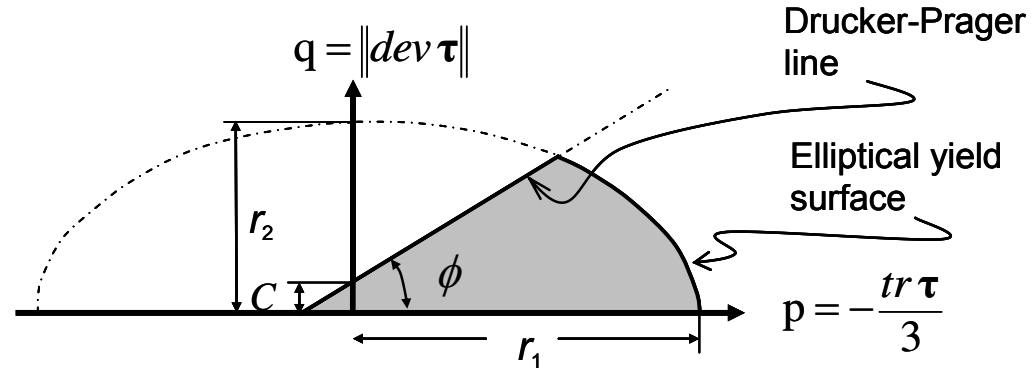

Fig.12 


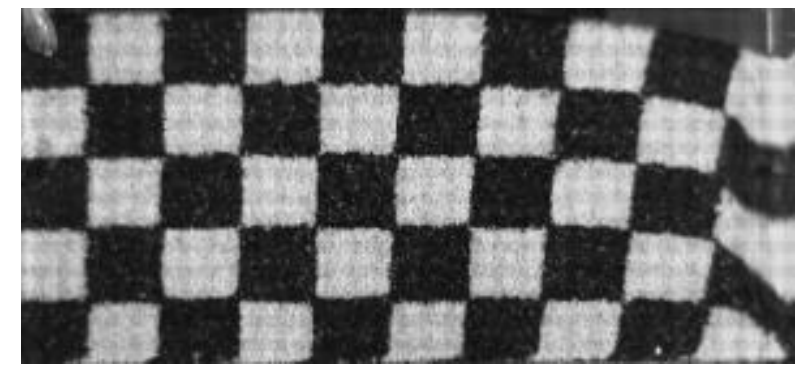

$\mathrm{a}$
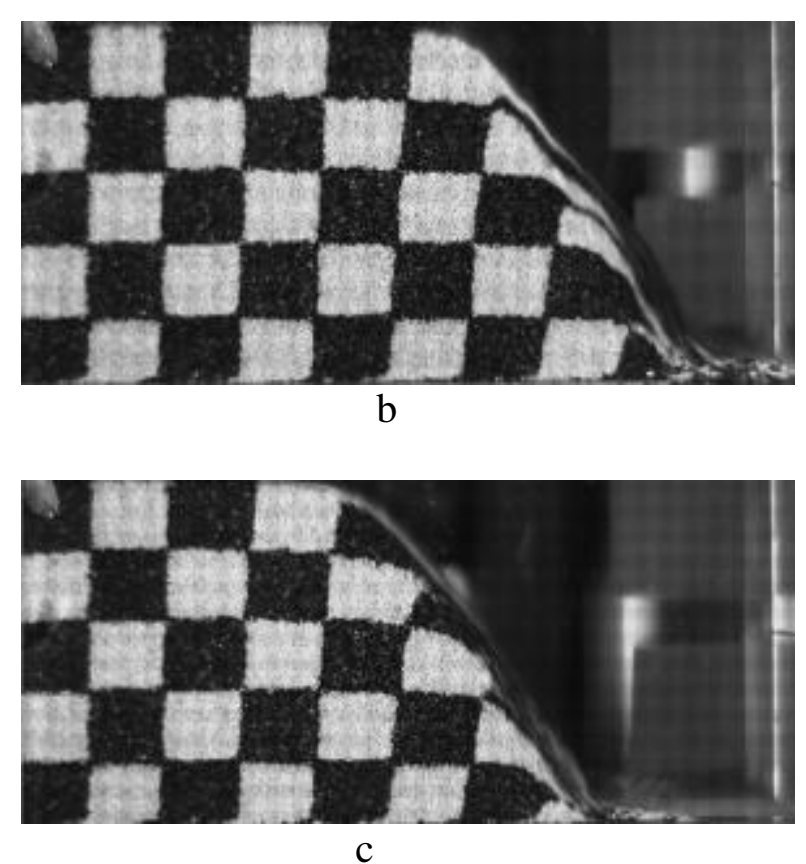

c

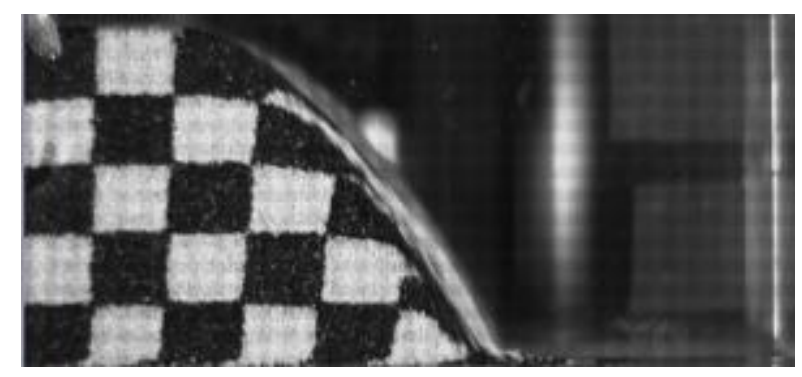

d
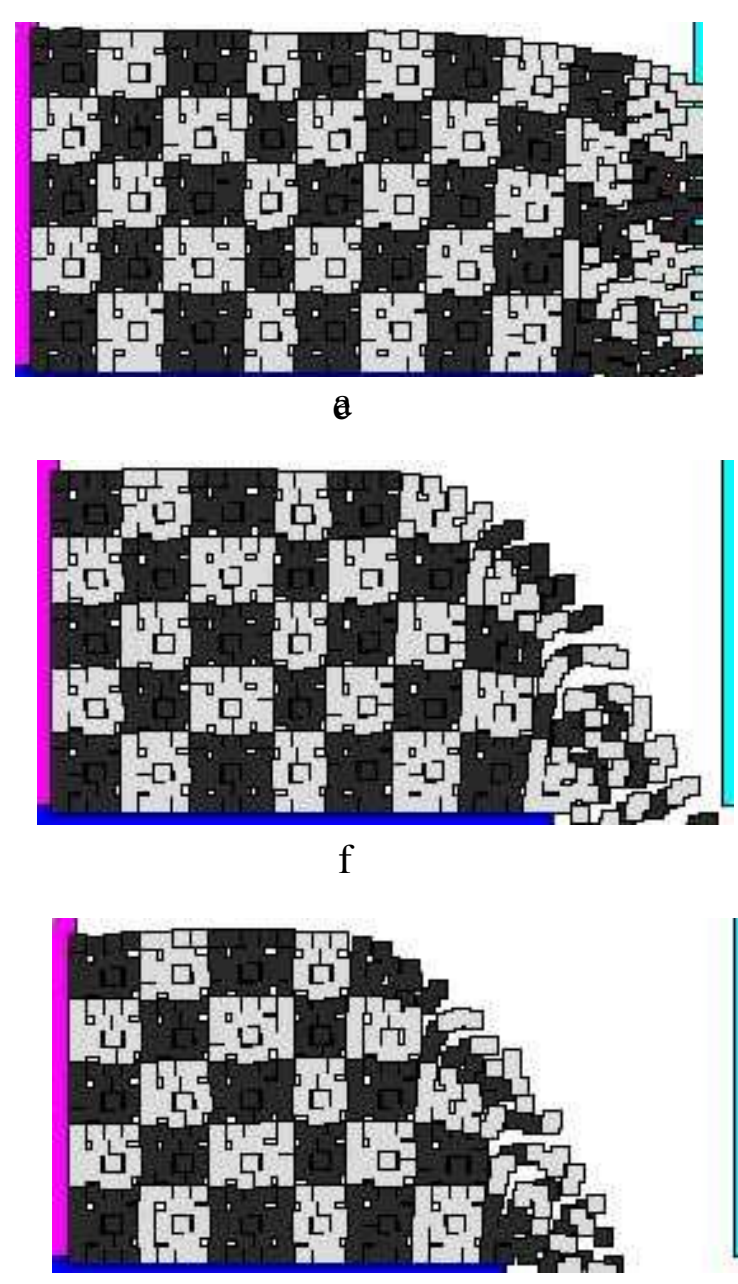

g

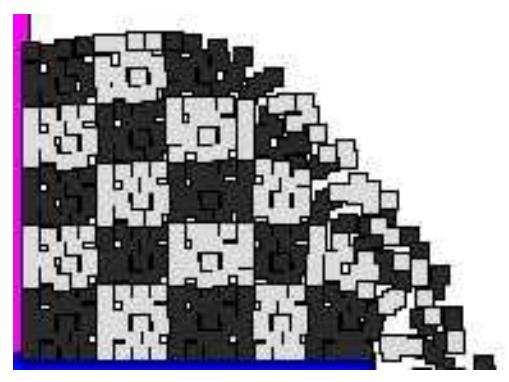

h

Fig.13 


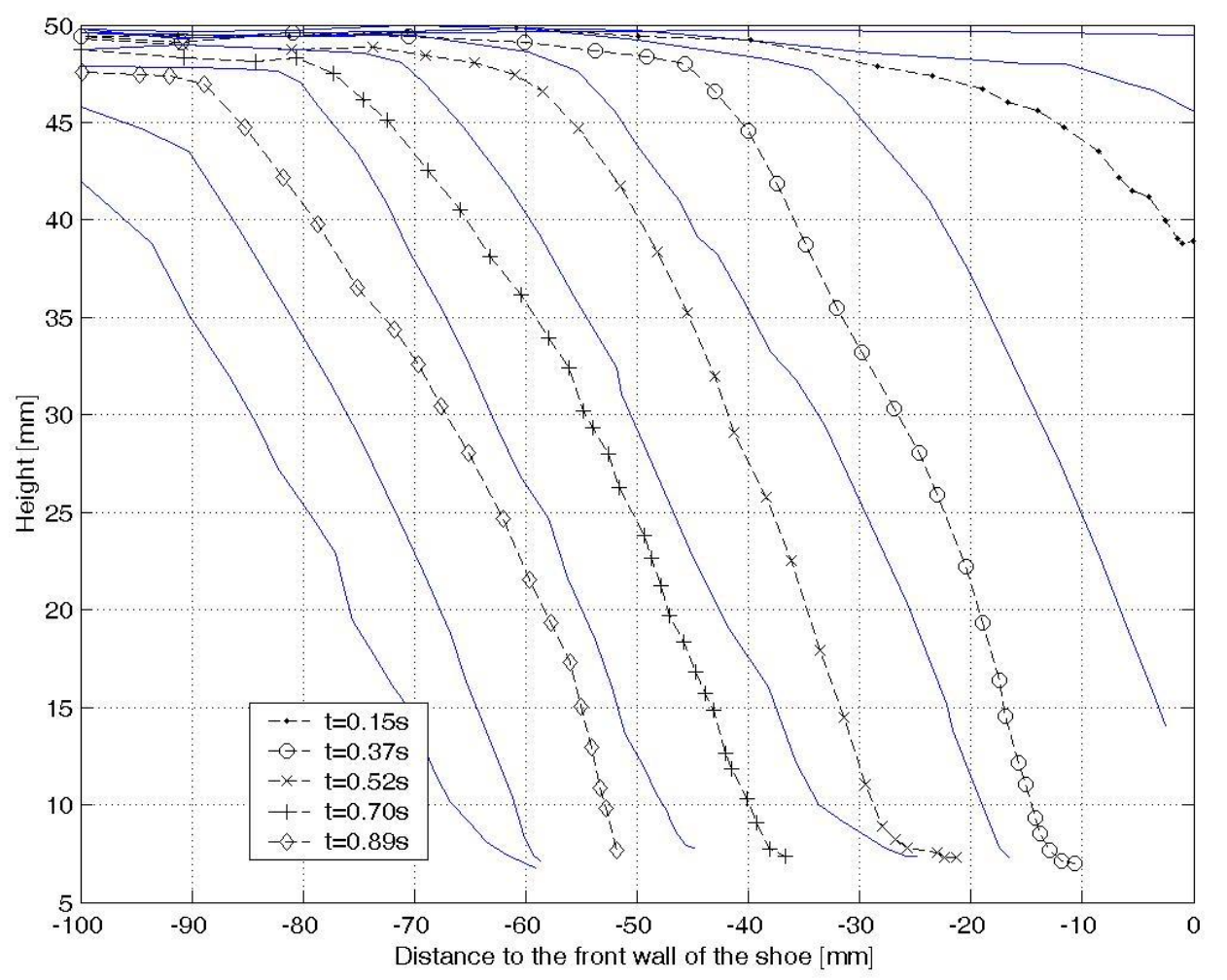

Fig. 14 


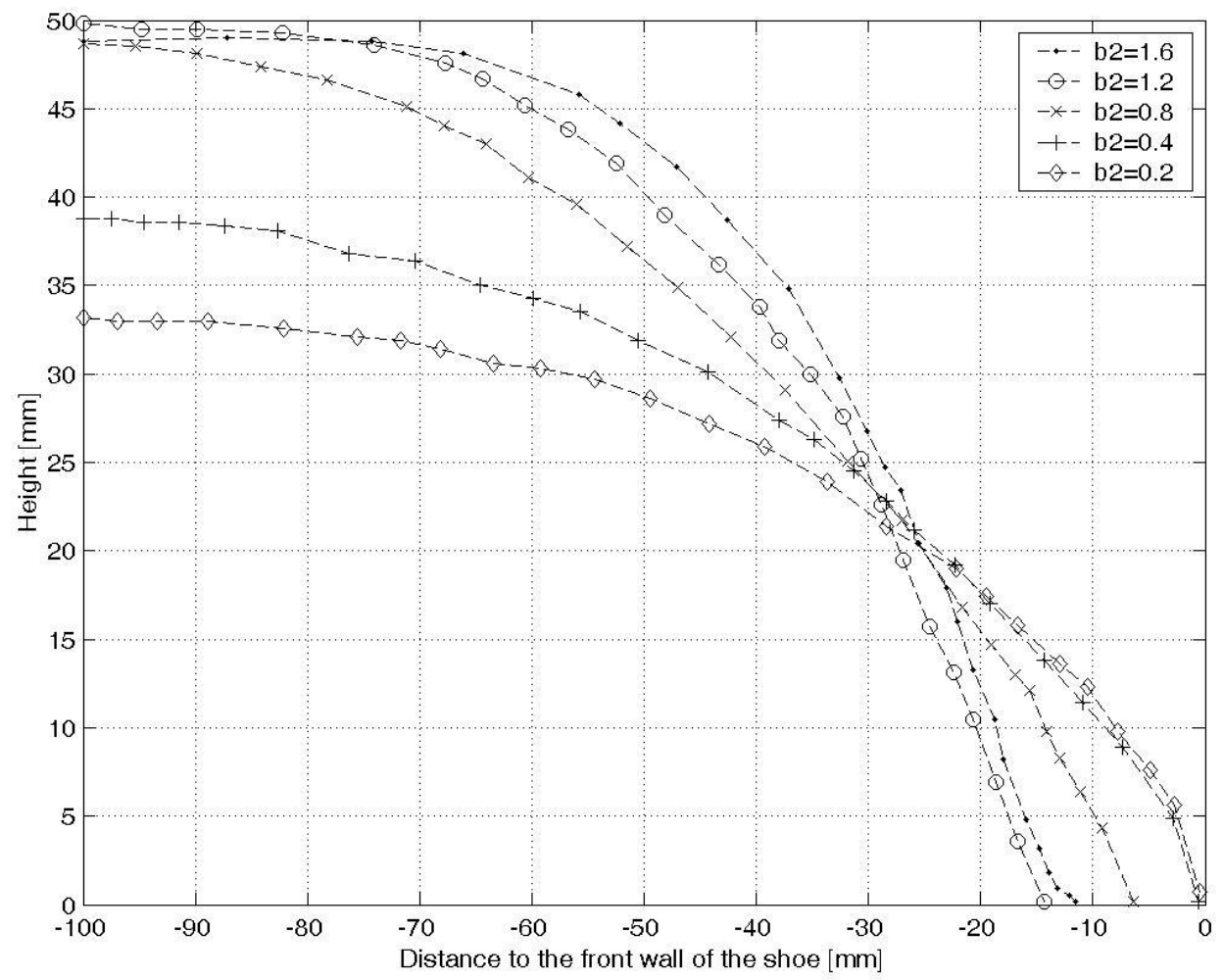

Fig. 15 

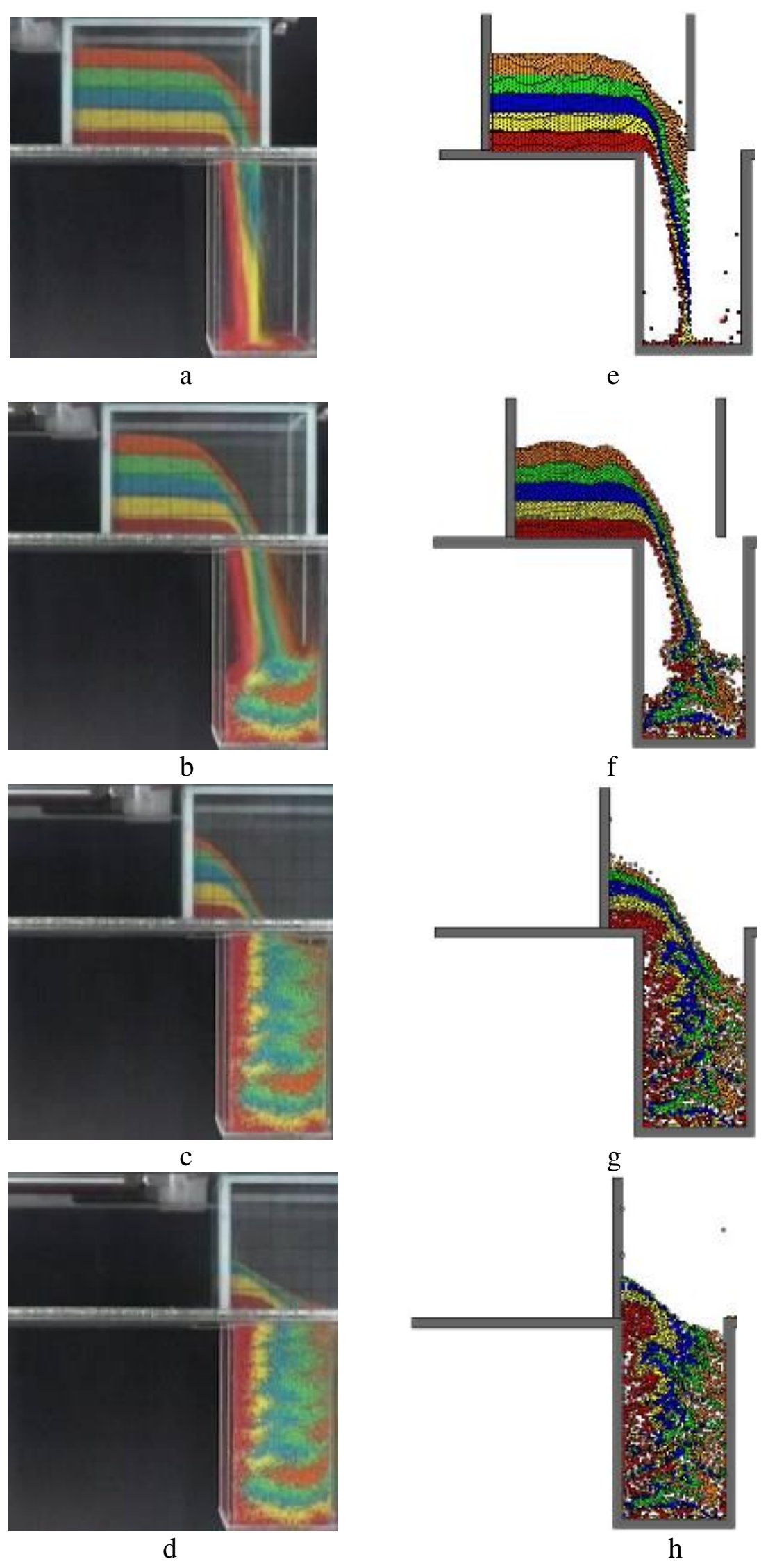

Fig.16 